\title{
CONTRIBUIÇÕES PARA UM BESTIÁRIO FEMININO EM PLAUTO
}

\author{
Carol Martins da RochA*
}

Universidade de Campinas

\begin{abstract}
Resumo. A disputa entre homens e mulheres é um dos motivos cômicos típicos da palliata, gênero a que pertencem as 21 comédias do poeta romano Tito Mácio Plauto (III-II a.C.). Assim, muitos dos enredos dessas peças giram em torno de uma verdadeira guerra, sobretudo, entre maridos e esposas. Buscando perceber de que maneira essa disputa entre os sexos é caracterizada, observamos exemplos de invectivas tanto de personagens femininos contra masculinos, como o contrário, nas peças Báquides, Cásina, Menecmos e O mercador. Nosso interesse principal diz respeito a uma possível construção de um repertório "bélico", envolvendo o uso recorrente de metáforas animais para caracterizar as mulheres.
\end{abstract}

Palavras-chaves. Plauto; comédia; mulheres; imagens de animais.

D.O.I. 10.11606/issn.2358-3150.v18i2p102-119

O CONFLITO ENTRE HOMENS E MULHERES É RECONHECIDAMENTE UM DOS motivos cômicos típicos da palliata, gênero a que pertencem as 21 comédias de Tito Mácio Plauto (III-II a.C.). ${ }^{1}$ Assim, em muitas das peças do poeta romano, parte significativa da ação gira em torno de uma verdadeira "guerra", sobretudo, entre maridos e esposas. ${ }^{2}$

\footnotetext{
* Doutora em Linguística (2015) pelo Instituto de Estudos da Linguagem da Universidade Estadual de Campinas, com estágio no Seminar für Klassische Philologie (Universität Heidelberg), ambos com apoio da Fundação de Amparo à Pesquisa do Estado de São Paulo. Este texto é uma versão revisada da comunicação apresentada no IV Colóquio do grupo de pesquisa Estudos sobre o teatro antigo (USP/CNPq), "As relações de poder no teatro greco-romano", realizado entre os dias 14 e 16 de agosto de 2012 na Universidade de São Paulo. Nele, apresenta-se parte dos resultados de nossa pesquisa de doutorado (à época em andamento) "De linguado a lingua(ru)da: gênero e discurso das mulieres plautinae" (FAPESP, processo n ${ }^{\circ}$ 2010/20403-4), sob orientação da Profa. Dra. Isabella Tardin Cardoso (IEL/Unicamp). O desenvolvimento de muitos dos aspectos aqui discutidos foram integrados à nossa tese (cf. Rocha 2015). Agradeço ao Prof. Dr. Paulo Sérgio de Vasconcellos e à Mariana Pini Fernandes pela leitura de uma versão prévia deste material e pelas valiosas sugestões.

“Artigo recebido em 25.set.2015 e aceito para publicação em 14.dez.2015.

${ }^{1}$ Para um panorama sobre a (discutida) carreira plautina, cf., por exemplo, Cardoso 2006, 26-8; Rocha 2010, 13-20.

${ }^{2}$ Exemplos de peças plautinas em que a disputa conjugal ocupa parte significativa do enredo são: Asinária, Cásina, Menecmos, O mercador (Cf. Hunter 1989, 90: "provavelmente os casamentos cômicos mais memoráveis são aqueles que Plauto apresenta em algumas peças (As., Cas., Men.,
} 
No palco, diversas são as manifestações representativas da opinião masculina em relação ao mal-estar causado pelas mulheres nessa disputa doméstica. A título de exemplo, podemos mencionar dois exemplos marcantes desse mote: na peça Asinária, Demêneto afirma que só consegue ser feliz quando a esposa está longe (As. 899-90o), ${ }^{3}$ e em Trinumo, Cálicles e Megarônides, rogando uma espécie de "praga", desejam um ao outro que as respectivas esposas lhes superem em anos de vida (Trin. 55-7). ${ }^{4}$

Segundo os personagens plautinos, os defeitos femininos são muitos: as mulheres falam demais, ${ }^{5}$ gastam muito e só pensam em luxo, ${ }^{6}$ perturbam os seus cônjuges... ${ }^{7}$ Essa gama de pontos negativos faz com que os maridos $^{8}$ expressem com frequência seu ponto de vista, contribuindo para fomentar a disputa por poder subjacente na relação entre homens e mulheres retratada no palco plautino. ${ }^{9}$ É o caso das peças de que vamos tratar, a saber, as comédias Báquides, Cásina, Menecmos e O mercador.

Entre as "armas" empregadas nessa disputa está, sem dúvida, a desqualificação da parte adversária. Interessa-nos, mais especificamente, a representação de uma opinião negativa em relação ao "inimigo" através do uso recorrente de metáforas envolvendo animais para caracterizar os personagens, sobretudo os femininos. Nesse sentido, observaremos, então, a presença desse recurso na fala de personagens masculinos sobre as mulheres. Em seguida, trataremos do mesmo recurso, mas expresso na fala de personagens femininos.

Esquematicamente, procuraremos delimitar, nas peças acima referidas, que animais são mencionados e a que tipo(s) cômico(s) (p. ex., meretrix,

Mer. e Mos.). Nessas peças, o ambiente conjugal é um campo de batalha" ("Perhaps the most memorable comic marriages are those which Plautus presents in a number of plays (Asin., Casina, Men., Merc. and Most.). In these plays the marital home is a battleground"). Sobre diferenças no tratamento dado ao tema por parte de Plauto e Terêncio, cf. Duckworth 1971, 282-5.

${ }^{3}$ Exemplos de outras passagens que atestam a alegria dos maridos pelo fato de suas esposas estarem distantes são: Mer. 543; Men. 152, 318 (cf. Segal 1987, 27).

${ }^{4}$ Sobre a presença de tal motivo cômico, cf. Duckworth 1971, 279-85; Segal 1987, 23-9; Hunter 1989, 83-95; Moore 1998, 158-80. Embora bastante recorrente na comédia, sabe-se que esse tipo de brincadeira não é exclusividade do gênero. No De Oratore de Cícero (2.69.278), por exemplo, temos a reprodução de uma piada, apresentada como exemplo da utilidade do humor na retórica, sobre um siciliano que pede ao colega mudas da figueira na qual sua esposa havia se enforcado. Quintiliano cita a mesma piada em sua Institutio Oratoria (6.3.88). Sobre este texto, cf. Miotti 2010, 124-5.

${ }^{5}$ Cf., p. ex., Aul. 123-6 (o curioso nessa passagem é que temos um personagem feminino, Eunômia, criticando características alegadamente femininas), Cas. 497-8, Rud. 905.

${ }^{6}$ P. ex., Aul. 497-502, 505-22.

${ }^{7}$ P. ex., Men. 110-8, Mer. 556-7, Rud. 905.

${ }^{8}$ Outros personagens masculinos, como escravos (p. ex.: Men. 193-5), e até mesmo mulheres (cf. nota 6), apresentam opinião negativa em relação aos personagens femininos.

${ }^{9}$ Cf. Hunter 1989, 83-95; Moore 1998, 158-80; Franko 2001, 169-88. 
matrona) eles são associados nas comparações ali presentes. Além disso, tencionamos observar nas comédias em apreço: (a) quais são os possíveis efeitos da menção a determinado animal nas comparações enunciadas; (b) que efeitos é possível depreender das imagens envolvendo animais que aparecem tanto na fala de personagens femininos quanto na de personagens masculinos e (c) a que elementos dramáticos das respectivas peças as comparações envolvendo animais estão associadas.

\section{FERAS INDOMADAS}

No início do segundo ato da peça $O$ mercador, o velho Demifonte narra o sonho que havia tido naquela noite. A cena apresenta, de forma metafórica, o imbróglio que norteia o enredo da peça:

Demifonte. Os deuses pregam uma peça nos homens de modo admirável e enviam sonhos admiráveis durante o sono..$^{10} \mathrm{Eu}$, por exemplo, na noite passada, em sonho, estive muito ocupado e fiquei atormentado. Parece que eu comprei uma bela cabra. Para que a cabra que eu já tinha em casa não fizesse mal a ela e para que não brigassem, se as duas ficassem no mesmo lugar, depois de tê-la comprado, parece que a confiei à guarda de um macaco. (Mer. 225-33; grifo nosso) ${ }^{11}$

Com o decorrer da peça, o público poderá perceber que, com seu relato, o velho antecipa de forma metafórica algo que efetivamente fará parte da ação: o fato de que ele comprará uma bela "cabra" (em latim, capra), e que a "cabra" que já habitava sua casa, muito provavelmente, não vai se dar bem com a nova aquisição. As cabras serão conhecidas nos próximos aconteci-

${ }_{10}$ "Miris modis di ludos faciunt hominibus/ mirisque exemplis somnia in somnis danunt" (225-6): o ThLL (V.2.1347) indica um enfraquecimento do sentido do termo exemplum na passagem plautina. Ernout (Plaute 1936, 108) traduz esses versos por "les dieux se jouent étrangement des hommes, et leur envoient dans leurs sommeil des songes bien étranges"; Nixon (Plautus 2002, 29) opta por "the Gods do make sport of us mortals in amazing ways! And amazing dreams they do send us in night". Em Plauto, o sonho é frequentemente relacionado ao engano dos sentidos (Frangoulidis 1994, 72-86; sobre Anfitrião, cf. Costa 2010). A presença de passagem bastante semelhante a essa d'O mercador na peça O cabo (593-613) foi comentada, no que diz respeito ao tratamento que Plauto supostamente teria dado ao modelo grego utilizado na produção das peças, por estudiosos como Marx (1899, viII.1-34); Leo (1912, 162-6); Enk (1932a, 7-21); Ernout (Plaute 1936, 89) e Fraenkel (2007, 133-9; 412).

${ }^{11}$ Salvo outra indicação, os textos latinos citados são os da edição de Ernout (Plaute 1933, 1936). "DEM. Miris modis di ludos faciunt hominibus/ mirisque exemplis somnia in somnis danunt./ Velut ego nocte hac quae praeteriit proxuma/ im somnis egi satis, et fui homo exercitus./ Mercari uisus mihi sum formosam capram./ Ei ne noceret quam domi ante habui capram,/ neu discordarent, si ambae in uno essent loco,/ posterius quam mercatus fueram, uisus sum/ in custodelam simiae concredere. 
mentos da comédia: a mais antiga é a esposa de Demifonte (cujo nome não se menciona no decorrer da peça); e a recém-chegada é Pasicompsa, meretriz - comprada por Eutico, filho do velho - pela qual Demifonte acabará se apaixonando.

Nos versos que citamos, o senex parece não diferenciar, em termos linguísticos, as duas mulheres em questão. Embora pertencentes a tipos bem diferenciados da palliata (meretrix e matrona) ${ }_{1}^{12}$ ambas são designadas apenas como capra. Cabe ressaltar que a menção ao animal é usada de forma metafórica ${ }^{13}$ e que essa qualificação se apresenta como recurso que recorre ao universo onírico. Nesse sentido, parece-nos que ali a representação de um humano por um animal não seria tomada como comparação de fato, ao menos não explicitamente, já que, por exemplo, não é desenvolvida de modo a designar aspectos específicos (físicos ou psicológicos) das mulheres em questão e de uma cabra. ${ }^{14}$ Destacamos ainda que nesse ponto d'O mercador ainda não se manifesta diretamente nenhuma opinião negativa em relação às mulheres, nem mesmo em relação à matrona - que, como veremos, não costuma ser elogiada no contexto plautino.

Como já previra em sonho, Demifonte vai até o porto, avista, por acaso, Pasicompsa (254-61), que havia sido trazida pelo jovem Eutico, e enamora-se por ela (262-3). Extasiado pela paixão repentina, o velho convence seu amigo Lisímaco a comprar a meretriz (467-8) e levá-la para sua casa, a

${ }_{12}$ Sobre o tipo da meretriz na comédia paliata, cf. Duckworth 1971, 258-61; Fantham 1975, 44-74; Fantham 2011, 143-75; Gilula 1980, 142-65. Sobre o tipo da matrona em Plauto, cf. Schuhmann 1977, 45-65; Moore 1998, 158-80; para exceções, cf. Cardoso 2001, 21-38.

${ }^{13}$ Chevallier $(1995,347-8)$ indica outras passagens, além dessa d'O mercador, em que Plauto recorre a metáforas envolvendo homens e animais em "esboços de fábula" ("esquisses de fables"): Aul. 229; Mos. 832; Rud. 595; Trin. 170-2.

${ }^{14}$ Em Plauto, o termo capra aparece apenas nessa peça (cf. Lodge 1962). Todas as ocorrências pertencem ao monólogo de Demifonte $(229,230,236,238,240,246,250,253,268)$ e se referem às mencionadas mulheres. Para Fraenkel $(2007,137)$, a falta de relação direta entre os animais citados por Demifonte em seu relato onírico e aspectos do enredo que justificassem a escolha de tais comparações indica má-adaptação do modelo grego por parte do comediógrafo romano: "ele [i.e., o relato] não contém elementos dramáticos ou algum tipo de éthos, contém apenas a reduplicação de um dado símile. Não podemos falar de uma 'estrutura simbólica' num caso em que percebemos apenas uma à $\lambda \lambda \eta \gamma$ $\rho \tilde{v} v$ ('alegoria') plana; isso sim, podemos perceber. Também não se deve pensar nos animais (como é possível em Rudens, peça em que o que se passa está de acordo com a natureza dos animais [mencionados]), mas apenas nos humanos por detrás deles, que são aludidos com a ajuda das figuras do sonho" ("it contains no dramatic element, no kind of ethos, only the reduplication of a given simile; we cannot speak of a 'symbolic framework' where we perceive only

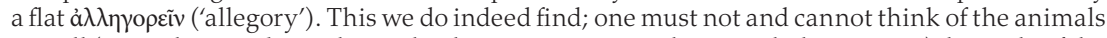
as well (as we do in Rudens, where what happens is in accordance with their nature), but only of the humans behind them, who are alluded to with the help of the figures from the dream"). A despeito da qualidade do tratamento que Plauto teria dado ao hipotético modelo grego d'O mercador questão de que não trataremos no momento -, acreditamos que a metáfora envolvendo animais nessa passagem da peça não cria meramente uma alegoria "plana", como afirma Fraenkel. Em nosso entender, tal designação resulta, como comentaremos adiante, em efeitos dramáticos que envolvem não apenas o enredo de tal comédia como outras alusões a animais no corpus plautino. 
fim de esconder a moça ali (544-5). O plano, entretanto, acaba em confusão. Doripa, esposa de Lisímaco, sem receber notícias do marido, volta do campo a fim de apurar o que está acontecendo (666-9). Ela ignora, porém, que o próprio marido abriga uma meretriz em sua casa, a pedido do amigo Demifonte, mesmo sem ter interesse algum pela moça (738). Contribui para o aumento da confusão a seguinte conversa, que ocorre em presença de Doripa, entre Lisímaco e o cozinheiro contratado para preparar o banquete. $\mathrm{O}$ trecho que destacamos começa com uma observação irônica do cozinheiro sobre a esposa do velho, mulher que ele acredita ser a meretriz comprada por Demifonte:

Cozinheiro Essa é sua amante, aquela que, como você me disse agora há pouco, enquanto fazia compras, você ama?

Lisímaco Você não vai ficar quieto?

Coz. É um tipo bastante atraente de mulher, mas, por Hércules, ela já está velha!

Lis. Por que você não vai para o inferno?

Coz. Ela não é de todo ruim.

Lis. Mas você é ruim.

Coz. Por Hércules, acho essa amante atraente.

Lis. Por que não vai embora? Eu não sou aquele que o contratou agora há pouco.

Coz. O quê? Por Hércules, é você mesmo sim.

Lis. Pobre de mim!

Coz. Sem dúvida sua esposa está no campo. Agora mesmo, você disse que a odiava como uma cobra.

Lis. Eu lhe disse isso?

Coz. Para mim mesmo, por Hércules.

Lis. Pelo amor de Júpiter! Esposa, eu nunca disse isso.

DORIPA E você ainda nega? Essas palavras deixam claro que você me odeia.

Lis. De fato, nego.

Coz. Não, ele não estava dizendo que odiava você, mas sim a esposa dele. Ele também estava dizendo que a esposa dele está no campo.

Lis. Esta é minha esposa. Por que você está sendo importuno?

Coz. Porque você diz que não me conhece. A não ser que você esteja com medo dela... (Mer. 753-68; grifo nosso) ${ }^{15}$

A graça no texto é evidente: a cada nova intervenção do cozinheiro, a situação de Lisímaco se complica. Ao tomar Doripa por Pasicompsa, o cozinheiro

\footnotetext{
${ }^{15} \mathrm{CO}$. Haecin tua est amica, quam dudum mihi/ te amare dixti, quom obsonabas? LY. Non taces?/ CO. Satis scitum filum mulieris; uerum hercle anet. LY. Abin dierectus? CO. Haud malast. LY. At tu malu's./ CO. Scitam hercle opinor concubinam hanc. LY. Quin abis?/ Non ego sum qui te dudum conduxi. CO. Quid est?/ Immo hercle tu istic ipsus. LY. Vae misero mihi!/ CO. Nempe uxor rurist tua, quam dudum dixeras te odisse atque anguis. LY. Egone istuc dixi tibi?/ CO. Mihi quidem hercle. LY. Ita me amabit Iuppiter,/ uxor, ut ego illud numquam dixi. DORIPA: Etiam negas?/ Palam istaec fiunt te me odisse. LY. Quin nego./ CO. Non, non te odisse aiebat, sed uxorem suam:/ Et uxorem suam ruri esse aiebat. LY. Haec east./ Quid mihi molestu's? CO. Quia nouisse me negas./ Nisi metuis tu istanc...
} 
encadeia uma série de julgamentos errôneos sobre a mulher. Tal sequência culmina na acusação por parte do cozinheiro de que Lisímaco havia dito que odiava a própria esposa como odeia uma cobra (anguis).

É de conhecimento do público plautino que, ao menos nas cenas decorridas no palco da peça, Lisímaco não teria feito tal comparação de fato. Por isso, a qualificação nada elogiosa para a esposa pode ser pensada como efetivamente de autoria de Lisímaco (expressa fora do palco), ${ }_{1}^{16}$ ou ainda, segundo entendemos, como mera invenção do cozinheiro visando a colocar o velho em situação constrangedora e, portanto, risível. ${ }^{17}$

Observar o efeito da designação da matrona como animal nessa cena afeta de maneira retroativa a compreensão da peça $O$ mercador: torna-se mais explícito o caráter pejorativo da associação entre cabras e mulheres, que à primeira vista parecia neutra, no relato do sonho de Demifonte. Também podemos pensar que as palavras do cozinheiro (usadas, pois, como recurso de obtenção de humor) remetem a um determinado repertório de qualificações tipicamente atribuídas a mulheres em comédias de Plauto, o qual envolve a comparação com animais.

\footnotetext{
${ }^{16}$ Agradecemos ao Prof. Dr. Rodrigo Tadeu Gonçalves por nos lembrar dessa possibilidade durante nossa apresentação oral. No entanto, note-se que, em seu comentário à passagem, Ernout (Plaute 1936, 141) sugere certa inconsistência na fala do cozinheiro: "é bastante estranho que Lisímaco tenha contratado um cozinheiro, e que ele tenha lhe feito tais confidências. Talvez ele quisesse suplantar Demifonte. Mas isso deveria ter sido dito em alguma outra passagem" ("il est assez étrange que Lysimaque ait engagé un cuisinier, et qu'il lui ait fait de telles confidences. Peut-être voulait'il prendre la place de Démiphon. Mais cela aurait dû être dit quelque part"). Já Norwood (1963, 40-1), ao analisar essa peça - embora use um tom "entusiasmado", sem apresentar, segundo nosso ponto de vista, justificativas precisas para tanto -, comenta, de maneira elogiosa, a cena de que tratamos: "a excelente farsa da cena do cozinheiro (741-82) é introduzida com perfeita habilidade: ele vem porque foi convocado, e ele foi convocado por uma razão essencial para o enredo" ("the superb farce of the cook's scene (741-782) is introduced with perfect skill: he comes because he has been summoned; and he has been summoned for a reason essential to the plot"). Sobre a função cômica do cozinheiro na Comédia Nova grega e romana, ver nota seguinte. ${ }^{17}$ Cf. Handley (1970, 1-42) sobre o cozinheiro como figura associada a riso na Comédia Nova grega e romana (aspecto sublinhado sobretudo na discussão que segue o artigo). Duckworth (1971, 262), em comentário mais geral sobre os cozinheiros em Plauto, destaca a mesma função: "o cozinheiro em Plauto é preeminentemente um personagem para causar riso" ("the cook in Plautus is preeminently a character to create laughter"). Ao tratar mais propriamente d'O mercador, o estudioso chega a afirmar que esta é uma das cenas de "humor brilhante" ("sparkling wit") da peça: "muitos críticos qualificaram a comédia como uma das produções mais pobres de Plauto. Ela tem, no entanto, muitas cenas de humor brilhante (p. ex., a tentativa de pai e filho de comprar a moça para "clientes" imaginários, o retrato de Pasicompsa como uma meretriz divertida e alegre, o engano do cozinheiro sobre Doripa), e no todo pode ser considerada uma farsa bastante divertida" ("many critics have rated the comedy as one of Plautus' poorest productions. It has, however, many scenes of sparkling wit (e.g., the attempt of father and son to buy the girl for imaginary "clients", the portrayal of Pasicompsa as a pert and amusing courtesan, the caterer's mistaken belief about Dorippa), and on the whole must be considered a highly entertaining farce"), Duckworth 1971, 167; grifo nosso).
} 
Referências a animais em outros autores da Antiguidade greco-romana já têm chamado a atenção de estudiosos modernos. ${ }^{18}$ No que diz respeito à presença do recurso na poesia plautina, ainda vamos verificar, numa próxima etapa de nossa pesquisa, até que ponto, de que modo e com que efeitos, tal repertório vale para as demais peças de nosso autor. ${ }^{19}$

No momento, a impressão é de que a pertinência de tal recurso a um repertório de descrição das mulheres plautinas é precisamente o que pode tornar verossímil (ao menos para a esposa de Lisímaco) a invenção do cozinheiro n'O mercador. Sobretudo se amparada numa espécie de "bestiário feminino" em Plauto, a referência à cobra corrobora a eficácia da farsesca estratégia de constranger o velho, diante da mulher com quem a comparação se faz. Além disso, se é verdade que a plateia supõe que o velho não enunciou tal comparação, temos, então, forte ironia dramática: o público estaria ciente da simulação de um dos personagens, bem como de que o velho não chamara a esposa de cobra, mas um dos personagens, a esposa, agiria sem saber da verdade sobre o fato.

Outro exemplo que corrobora a existência de um repertório mais vasto de comparações entre mulheres e animais na paliata plautina é uma brincadeira presente na peça Cásina. Com a chegada do velho Lisidamo em cena, Olímpio, seu escravo, zomba do dono:

Lisidamo O que é isso? Com quem está discutindo, Olímpio?

Olímpio Com aquela mesma com quem você sempre discute.

Lis. Com a minha esposa?

Ol. Como você pode chamá-la de "minha esposa"? Você é quase como um caçador: dia e noite passa a vida em companhia de uma cadela.

(Cas. 317-20; grifo nosso) ${ }^{20}$

Segundo as edições comentadas da peça por MacCary e Willcock (Plautus 1976, 136-7) e Chiarini (Plauto 1998, 104), a referência à mulher como cadela seria "brincadeira" comum entre os antigos, que lembra um verso da Ilíada em que Helena mesma se compara a esse animal (Il. 6.344; 356). ${ }^{21}$

\footnotetext{
${ }^{18}$ Quanto a bestiários na Antiguidade em geral, cf. Keller 1909, 1913; sobre esse recurso na poesia invectiva de Arquíloco, cf. Corrêa 2010; na Antologia palatina, cf. Norman 1928; na épica de Virgílio, cf. Bonnet 1958-1959. Na obra Homme et animal dans l'antiquité romaine, organizada por R. Chevallier, há um capítulo, composto de cinco artigos, dedicado ao estudo desse tema na literatura antiga.

${ }^{19}$ Esse é o tema de nosso estágio de pesquisa no exterior "Bestiário feminino e discurso das mulieres plautinae", desenvolvido na Universität Heidelberg (Alemanha), também com auxílio da FAPESP (processo n 2012/ 21554-1), sob orientação da Profa. Dra. Isabella Tardin Cardoso (IEL/ Unicamp) e supervisão do Prof. Dr. Jürgen Paul Schwindt (Universität Heidelberg).

${ }^{20}$ LY. Quidistuc est? quicum litigas, Olympio?/OL. Cum eadem qua tu semper. LY. Cum uxore mea?/ OL. Quam tu mi uxorem? quasi uenator tu quidem es;/ Dies atque noctes cum cane aetatem exigis.

${ }^{21}$ O trecho homérico citado traz o termo kũvú ("cão, cadela"). No comentário ao canto vi da obra homérica, Graziosi e Haubold (Homer 2010, 176) afirmam que o termo é um insulto comum
} 


\section{Em uma passagem de Menecmos, surge nova comparação entre mulher e cadela, agora retomando de maneira direta o mito de Hécuba:}

MeneCmo II $^{22}$ Você não sabe, mulher, por que os gregos chamavam Hécuba de cadela? MATRONA Não, não sei.

$<$ Men. II $>$ Porque Hécuba fazia o que você faz agora: lançava todas as injúrias em quem quer que avistasse. Dessa maneira, e bem merecidamente, ela passou a ser chamada Cadela..$^{23}$

(Men. 714-8; grifo nosso) ${ }^{24}$

\section{Como se pode notar, brinca-se aqui com o substantivo comum canis ("cão, cadela") em referência ao episódio mitológico, segundo o qual, em fontes e versões diversas, Hécuba é associada a uma cadela. ${ }^{25}$ É difícil afirmar ao}

na épica e que Helena é o único personagem a aplicar o termo a si mesmo (cf. Il. 3.180; 6.356 e Od. 4.145). Segundo Dutsch (2008, 81-2), a metáfora envolvendo a comparação com a cadela seria frequentemente usada ("a metaphor commonly used") para descrever o comportamento nada agradável das mulheres. Ainda segundo a autora, o uso de tal comparação também pode ser justificado por cena anterior da peça Cásina (235-50), em que Cleóstrata "fareja" o perfume (abundante) do marido.

${ }^{22}$ Nas edições consultadas, convencionou-se diferenciar a fala dos dois Menecmos, irmãos gêmeos e de mesmo nome, apondo-se os algarismos romanos I e II aos respectivos nomes; na edição de Ernout (Plaute 1936, 12), por exemplo, a lista de dramatis personae traz MENAECHMVS II (SOSICLES).

${ }^{23}$ Na edição de Ernout (Plaute 1936, 57) e na de Gratwick (Plautus 1993, 104), o termo canis é grafado com inicial em maiúscula. Embora os editores não explicitem o motivo de tal escolha, acreditamos que a interpretação é de que o verbo appellare (718) aqui tem o sentido de nomear nesse caso, o termo Canes seria tratado como sendo nome próprio (cf. sentido 8 do verbete appello ${ }^{2}$ do OLD, que cita essa passagem plautina). As edições de Moseley e Hammond (Plauti 1975, 98) e Nixon (Plautus 1988, 438-9), que traduz o termo por "bitch", não adotam a grafia em maiúscula na inicial do termo.

${ }^{24}$ MEN. Non tu scis, mulier, Hecubam quapropter canem / Graii esse praedicabant? MA. Non equidem scio./ <MEN.>: Quia idem faciebat Hecuba quod tu nunc facis./ Omnia mala ingerebat, quemquem aspexerat;/ itaque adeo iure coepta appellari est Canes.

${ }^{25}$ Nos textos antigos que mencionam o mito de Hécuba transmitem-se suas diferentes versões. Na tragédia Hécuba de Eurípedes (1261-5), de acordo com a profecia narrada por Polimestor, a heroína torna-se um cão de olhos de fogo ao subir no mastro do navio de onde seria atirada ao mar para a morte. Nas Metamorfoses de Ovídio (13.565 e ss.), Hécuba, ao ser apedrejada pelos Trácios, inicialmente começara a se transformar em cão mordendo as pedras lançadas e, depois, ao tentar falar, apenas latia. No fragmento 968 atribuído a Eurípedes (cf. suplemento de B. Snell em Nauck 1964,1027), a esposa de Príamo é uma cadela, figura emblemática da deusa-feiticeira Hécate. Segundo Collard (Euripides 1991, 197-8), a passagem euripidiana seria o primeiro registro literário da transformação de Hécuba em cão. Além disso, o estudioso afirma que tal transformação é invenção do próprio tragediógrafo. Para os registros de Hécuba na literatura greco-latina, cf. Grimal 1963, 12-3. Para mais informações sobre a transmissão do mito de Hécuba, cf. a edição de Frazer da Biblioteca de Apolodoro (Apollodorus 1921, II.241 n.4). Sobre a transformação de Hécuba em cão, cabe ainda mencionar a afirmação de Roscher (1884-1936, 1882-3): "os antigos explicam a história da transformação em cachorro da seguinte maneira: Hécuba devido a seu discurso invectivo - o cão é tido como animal latrabile Mythogr. lat. 3.9 .8 (Plaut. Menaechm. 5.1.14) ou devido a seu triste destino (...Pomp. Mel. 2.26, Dio Chrysost. 11.193) teria sido chamada de cadela ou, como uma cadela, teria sido morta por apedrejamento" ("die Alten erklären die Sage von der Verwandlung in einen Hund so, dass Hekabe entweder wegen ihrer Schmäreden - der Hund gilt als animal latrabile Mythogr. lat. 3.9.8 - (Plaut. Menaechm. 
certo se, ou até que ponto, o heterogêneo público plautino, como um todo, teria acesso ao teor mitológico aludido. ${ }^{26}$ Mas, de todo modo, certamente os espectadores que assistissem a ambas as peças notariam alguma referência entre elas. Por exemplo, os da reapresentação póstuma de Cásina ${ }^{27}$ que tivessem conhecimento de Menecmos poderiam, ${ }^{28}$ ao ouvir em Cásina uma referência à mulher como cadela, lembrar-se da passagem semelhante em Menecmos. De todo modo, não queremos insistir na percepção dessa referência específica pelo público que assistia aos ludi scaenici de então: reconhecemos que tal hipótese é bastante incerta, ${ }^{29}$ até porque não podemos indicar com exatidão a cronologia exata da primeira apresentação de cada comédia plautina. Nosso interesse é apontar que havia essa possibilidade de um repertório comum envolvendo animais o qual, ao ser evocado, reforçaria os efeitos de humor nas peças respectivas.

Ainda podemos pensar que a existência de tais referências comuns entre as peças não contribui somente para uma maior comicidade da cena. A reiteração também ajuda a percebermos a possibilidade de haver esse tipo de alusão a um repertório de animais que caracterize personagens femininos, ou, em outras palavras, que contribua para que associações entre animais e mulheres funcionem como tópoi dentro do corpus plautino.

Citamos, então, outra passagem de Menecmos em que a mesma comparação entre mulher e cadela (aqui, envolvendo mais diretamente a matrona) se apresenta. O personagem Menecmo II, sem perceber que era confundido com o irmão gêmeo homônimo que procurava (e muito menos

5.1.14) oder wegen ihres traurigen Loses (...Pomp. Mel. 2, 26. Dio Chrysost. 11, 193) Hund gennant oder wie ein Hund durch Steinigung getötet worden sei"; Tzetz. ad Lycophr. 315. Dictys 5, 16").

${ }_{26}$ Para uma postura cética quanto ao conhecimento do público plautino de aspectos concernentes à mitologia e à cultura da Grécia, cf. Jocelyn 2001, 261-96. Cardoso (2005, 90-3) discute brevemente a postura do estudioso em relação ao assunto, relativizando-a.

27 "Nós, depois que percebemos, por conta do rumor popular, que vocês esperam ansiosamente pelas peças plautinas, apresentamos dele uma antiga comédia que vocês, que estão em idade mais avançada, já aplaudiram. Pois, dentre os mais jovens, eu sei, não há quem a conheça. Mas faremos de tudo para que sejam a ela apresentados. Da primeira vez que esta peça foi encenada, venceu todas as outras" ("Multo sunt nequiores quam nummi noui./ Nos postquam populi rumore intelleximus/ studiose expetere uos Plautinas fabulas,/ antiquam | eius edimus comoediam,/ quam uos probastis qui estis in senioribus./ Nam iuniorum qui sunt, non norunt, scio; uerum ut cognoscant dabimus operam sedulo./ Haec cum primum acta est, uicit omnis fabulas", Cas. 11-17). Cf. Rocha 2010, 13-17.

${ }^{28}$ Segundo Paratore $(1983,38)$, a peça Menecmos seria uma das mais antigas de Plauto, escrita em 206 a.C. O estudioso italiano aventa uma cronologia para as peças plautinas, mas hoje é notório que o tema não é ponto pacífico. Esse tipo de hipótese, em geral, é amparado em pressupostos especulativos, como a de uma suposta evolução do estilo da poesia plautina.

${ }_{29}$ São incertezas como essas - quer em relação ao conhecimento mitológico que o público teria, quer em relação à cronologia das comédias plautinas - que podem dificultar uma leitura intertextual das passagens com referências a animal até aqui apresentadas. Para uma reflexão sobre limites de aplicação de abordagem intertextual aos textos de Plauto, cf. Costa 2008, 571-84. 
que este era casado), tenta se livrar da mulher que - também sem saber do duplo - afirma ser sua esposa. Nesta altura, o confundido finge estar enlouquecendo diante da suposta esposa e do suposto sogro:

Menecmo Evoé! Brômio! ${ }^{30}$ Para qual floresta me chama para caçar? Ouço, mas não posso partir deste lugar: uma cadela raivosa me guarda à esquerda; detrás, porém, este bode fedorento, ${ }^{31}$ que muitas vezes em sua vida arruinou um homem inocente com falso testemunho.

(Men. 836-40; grifo nosso) ${ }^{32}$

Surge aqui mais uma vez, e novamente com evocação à mitologia, ${ }^{33}$ a comparação entre a mulher e cadela. Tem-se, assim, outra ocorrência enfática desse lugar-comum relacionando mulher a animal, também com efeito de humor. Na passagem, ainda se faz referência a outra comparação comum no palco plautino, a saber, a semelhança entre homens velhos e caprinos, de que passamos a tratar em seguida.

\footnotetext{
${ }^{30}$ "Eubi atque heu ${ }^{\dagger}$ Bromie" (836): o trecho é alvo de correção (cf. aparato crítico de Gratwick (Plautus 1993, 110) e de Ernout (Plaute 1936, 63)). Bromie (835) é vocativo de Bromius, um dos nomes de Baco.

${ }^{31}{ }^{+} \operatorname{Ircosalus}^{\dagger}$ (839): o trecho é pouco seguro, e sua emendatio é bastante discutida. Ernout (Plaute 1936, 64 n.1) afirma que a lição ircosalus, indicada nos manuscritos B, C e D, não tem sentido ("la leçon ircosalus des manuscrits n'a pas de sens") e que, pelo fato de algumas das correções sugeridas não serem impositivas, ele preferiu traduzir o texto latino como se a forma apresentada fosse hircus olidus (embora o texto editado apresente ${ }^{\dagger}$ ircosalus ${ }^{+}$). Em seu aparato crítico, o editor francês indica as opções hircus ("bode") (Beroaldus 1503); olidus ("fétido") (Seyffert 1868); e a sugestão squalus ("sujo") de F. Schoell (1889), que também comenta a passagem: "talvez esteja subjacente algum composto cômico, por exemplo hircasellus" ("fortasse latet comicum aliquod compositum, uelut hircasellus"). Gratwick (cf. Plautus 1993, 215-6), cuja edição registra o termo no verso 838, opta por "ille Cerco $<$ p $>$ s al $<$ i $>$ us" e sugere como tradução algo como "aquele homem-macaco ali" ("that monkeyman besides"). O editor afirma que as tentativas de ler o texto corrompido do manuscrito P como hircus não são convincentes (e indica o artigo de Barr 1966, que discute algumas sugestões de edição). À sua opção, Gratwick acrescenta uma breve explicação sobre os Cércopes (povo transformado por Júpiter em macaco e aprisionado na ilha de Pitecusa (atualmente conhecida como Ísquia), como castigo por traição). O fato de algumas das sugestões de emendatio propostas para esse verso envolverem a menção a um animal (quer bode, quer macaco) corrobora nossa impressão de que vale a pena investigar mais amplamente a existência de um bestiário em Plauto.

${ }^{32} \mathrm{MEN}$. ${ }^{\dagger}$ Eubi atque heu ${ }^{\dagger}$ Bromie, quo me in siluam uenatum uocas?/ Audio, sed non abire possum ab his regionibus, / ita illa me ab laeua rabiosa femina adseruat canis;/ poste autem illic ${ }^{+}$ircosalus $^{\dagger}$, qui saepe aetate in sua/ perdidit ciuem innocentem falso testimonio.

${ }^{33}$ Gratwick afirma que, seja qual for a correção no v. 836 (sugere-se euhoe em vez de eubi), os termos correspondem a lamentos enunciados em cultos ao deus Baco. Segundo o estudioso, a audiência plautina certamente reconheceria tais referências, já que esse tipo de culto tinha um número crescente de devotos em Roma durante o período da carreira de Plauto (cf. Plautus 1993, 215).
} 


\section{O OUTRO LADO DA MOEDA: OVELHAS VELHINHAS}

Também as mulheres usam comparações em seu discurso, quer direta, quer indiretamente. Observaremos que uma brincadeira recorrente com os senes das peças de Plauto também envolve a menção a animais. ${ }^{34}$

Na passagem de Menecmos acima citada, se aceitarmos a leitura de Ernout, o velho sogro do Menecmo que vivia em Epidamno é chamado de "bode fedorento" por um personagem masculino. Já na peça O mercador, o velho Demifonte, referido por seu vizinho Lisímaco, recebe alcunha diferente:

Lisidamo Por Hércules, acredito que você é valiosa, ${ }^{35}$ mesmo já em idade madura, pois sabe cumprir seu ofício, mulher.

PAsicompsa Por Pólux, aprendi pela experiência. Não permitiria que meu trabalho fosse repreendido.

Lis. Ah, por Hércules, aí está! É isso. Vou lhe dar uma ovelha, de sessenta anos, que vai ficar por sua conta. ${ }^{36}$

PAs. Tão velhinha, meu senhor.

Lis. É de raça grega. Se você cuidar dela, é boa demais, dá lã que é uma beleza. (Mer. 521-6; grifo nosso) ${ }^{37}$

A brincadeira começa nas palavras de Lisímaco, aliado de Demifonte. Mas, ressaltamos, é um personagem feminino (a meretriz Pasicompsa) que complementa a caracterização de tal ovelha (ouis) com um adjetivo tão especial: uetulus, diminutivo de uetus ("velho(a)"). Interessante é que a princípio a comparação entre o velho e uma ovelha não é enunciada exatamente pela meretriz, mas sim por Lisímaco, também um velho! A meretriz apenas corrobora a qualificação ao usar o termo uetulus na forma feminina (uetulam, 525). Ou seja, a meretriz trata o velho por "ovelha velhinha".

A partir dessa passagem, num primeiro momento, poderíamos dizer então que a comparação entre velho e ovelha é introduzida na ação como uma

${ }^{34}$ Para interessante abordagem sobre o tratamento dado aos senes em Plauto, cf. Bianco 2003. Sobre a comparação com animais, conferir especificamente os capítulos "Il 'bestiario' del vecchio" $\mathrm{e}$ "Hircus et ovis. Caratterizzazioni animalesche della vecchiaia" da mesma obra.

35 "Bonae (...) frugi" (521): o sentido da expressão, segundo o OLD (cf. sentido 5b do verbete frux), é "ter mérito ou valor, virtuoso, honesto, sóbrio, firme, econômico ou similar" ("having merit or worth, virtuous, honest, sober, steady, thrifty, or sim."). Ernout (Plaute 1936, 126) optou pela tradução "bonne e honnête travailleuse".

${ }^{36}$ Peculiarem (525): segundo o OLD, o sentido legal do termo peculiar é relacionado ao pecúlio (peculium) de determinada pessoa. Como sabemos, o pecúlio incluía tanto bens materiais, quanto escravos e até mesmo filhos. Dessa maneira, Lisímaco dá a entender que o velho passaria a fazer parte dos bens da meretriz.

${ }^{37}$ LY. Bonae hercle te frugi arbitror, matura iam inde aetate,/ quom scis facere officium tuum, mulier. PA. Pol docta didici;/ operam accusari non sinam meam. LY. Em, istaec hercle res est;/ ouem tibi eccillam dabo, natam annos sexaginta,/ peculiarem./ PA. Mi senex, tam uetulam? LY. Generis graecist;/ eam si curabis, perbonast; tondetur nimium scite. 
"opinião" masculina. Contudo, ao lermos o seguinte diálogo entre as irmãs da peça Báquides, vemos que tal tratamento pode refletir também o julgamento de mulheres em relação a personagens pertencentes ao tipo do velho:

BÁQUIDE Quem, com tanto barulho e bagunça, me chama [pelo nome] e bate à porta? Nicobulo Eu e ele.

BÁQ. O que há então, por favor? Quem arrastou essas ovelhas para cá?

Nic. Essas desqualificadas estão nos chamando de ovelhas.

IRMÃ O pastor delas está dormindo, pois [elas] vieram para longe do rebanho balindo.

BÁQ. Mas, por Pólux, estão brilhando, as duas não parecem nem um pouquinho sujas.

IR. De fato, as duas, com certeza, foram tosquiadas.

Filóxeno Parece que elas estão rindo de nós!

Nic. Deixe-as à vontade.

BÁQ. Você acha que elas são tosquiadas três vezes ao ano?

IR. Por Pólux, esta, com certeza, foi tosquiada duas vezes hoje.

$<$ BÁQ.> São velhinhas decrépitas.

IR. Acredito que elas já foram boas.

BÁQ. Está vendo como elas nos olham atravessado?

$<$ Ir.> Por Castor, acho que elas não têm nenhuma malícia.

FIL. É o que merecemos por termos vindo aqui.

BÁQ. Que sejam levadas para dentro então.

IR. Não sei por que razão: elas não têm leite, nem lã. Deixe-as paradas aí em pé. (Bac. 1120-34; grifo nosso) ${ }^{38}$

Como vemos, em Báquides são as próprias meretrizes que comparam os velhos da peça, Filóxeno e Nicobulo, a ovelhas. A brincadeira vai além, e as irmãs continuam descrevendo esse rebanho: as ovelhas balem (palitantes, 1123), estão brilhando (nitent, 1124; haud sordidae, 1124), foram tosquiadas (attonsae, 1125; tonsitari, 1127; detonsa, 1128), mas são decrépitas (thimiamaet, 1129), não dão leite, nem lã (nec lac[tem] nec lanam ullam habent, 1134).

Interessante é notar como a exploração da metáfora do velho como ovelha, desenvolvida inicialmente pela menção ao animal e, em seguida, especificando-se características a ele relacionadas, é apresentada de modo hábil. ${ }^{39} \mathrm{O}$ modus operandi da qualificação dos velhos como ovelhas envolve

\footnotetext{
${ }^{38}$ BA. Quis sonitu ac | tumultu tanto [nomine] nominat me atque pultat aedis?/ NI. Ego atque hic. BA. quid hoc est negoti nam, amabo?/ quis has huc ouis adegit?/ NI. Ouis nos uocant pessumae. SO. Pastor harum/ dormit, quom [haec] eunt a pecu palitantes./ BA. At pol nitent; haud sordidae uidentur ambae./ SO. Attonsae hae quidem ambae usque sunt. PHI. Vt uidentur/ deridere nos!/ NI. Sine suo usque arbitratu./ BA. Rerin ter in anno tu has tonsitari?/ SO. Pol hodie altera iam bis detonsa certo est./ <BA.> Vetulae sunt tthimiamet. SO. At bonas fuisse credo./ BA. Viden limulis, obsecro, ut intuentur? $<1130><$ SO. $>$ Ecastor sine omni arbitror malitia esse./ PHI. Merito hoc nobis fit, qui quidem huc uenerimus./ BA. Cogantur quidem intro. SO. Haud scio quid eo opus sit;/ quae nec lac[tem] nec lanam ullam habent; sic sine astent.

${ }^{39}$ Barsby (Plautus 1991, 186) afirma que é pouco provável que a passagem que envolve a metáfora do velho como ovelha não seja em grande parte ou mesmo completamente plautina. Segundo o autor, não há paralelo de uma imagem desenvolvida tão amplamente em Menandro.
} 
características que evidenciam não só a idade dos personagens, mas também elementos do enredo da peça. A menção da tosquia retoma o fato de que Nicobulo fora roubado por Crísalo. O próprio velho relata a artimanha do escravo, ao anunciar que teria sido "tosquiado" por ele:

Nic. Crísalo dilacerou-me ${ }^{40}$ hoje, Crísalo me arrancou os espólios, ${ }^{41}$ a mim, um miserável. Esse criminoso, como quis, pelou-me, ${ }^{42} \mathrm{eu}$, um bobo, até o ouro com seus espertos enganos.

(Bac. 1094-5) ${ }^{43}$

À parte o contexto bélico dos verbos lacerauit (1094) e spoliauit (1094), sua associação com attondit (1095), cuja semântica envolve a ideia de "tosquiar" ou, para usarmos uma metáfora mais comum em português atual, de "pelar" alguém, ou seja, roubar, a ponto de deixar a pessoa sem nada, "pelada", é estratégica. $\mathrm{O}$ verbo attondeo também aparecera na passagem comentada anteriormente, em que as meretrizes comparam os velhos a ovelhas. Dessa maneira, acreditamos que o mote das ovelhas tosquiadas parece já ter sido introduzido indiretamente na peça antes mesmo que a comparação entre senes e oues fosse enunciada de fato pelas meretrizes. ${ }^{44}$

Dado que tal comparação senes/oues é recorrente na obra plautina (já que, como vimos, surge também n'O mercador), podemos pensar que nessa passagem de Báquides emprega-se uma brincadeira familiar ao público plautino. Se é assim, é possível constatar novamente a presença de um repertório de animais que caracteriza personagens plautinos, nesse caso, os velhos. Tal constatação corrobora nossa hipótese de que esse tipo de associação funciona como tópos na comédia plautina.

Por fim, a brincadeira com as ovelhas enunciada pelas irmãs em Báquides nos leva a crer que especificamente esse tópos, que relaciona a imagem

${ }^{40}$ Lacerauit (1094): note-se a polissemia do verbo lacero que significa não apenas "ferir", "lacerar", como "arrancar (os cabelos, p. ex.)" (cf. OLD). Tentamos retomar esse sentido de arrancar ao traduzir spoliauit como "arrancou os espólios", cf. nota seguinte.

${ }^{41}$ Spoliauit (1094): o verbo spolio significa, inicialmente, "despir", "desnudar" (cf. sentido 1 do verbete spolio do $O L D$ ), mas também tem conotação militar de tirar as armas do inimigo, pilhá-lo (cf. sentido 2 do mesmo verbete). O uso do verbo com essa conotação na passagem confirmaria o resultado do ludíbrio, comparado com façanha heroica pelo próprio Crísalo, ao longo da peça. O tom de Glorifizierung, representação exagerada que o seruus callidus costuma fazer de si mesmo (Fraenkel 2007, 165-7) já está presente na peça como um todo, sobretudo nas odes em que o escravo narra suas "proezas" ao longo da peça (cf. p. ex., 170-7; 640-66).

${ }^{42}$ Attondit (1094): tentamos reproduzir a polissemia do verbo attondere que significa não apenas "tosar" (cf. sentido 1 do verbete attondeo do OLD), como também "despojar" (cf. sentido 2a do mesmo verbete).

${ }^{43}$ NIC. Chrysalus med hodie lacerauit, Chrysalus me miserum spoliauit./ Is me scelus auro usque attondit dolis doctis indoctum ut lubitumst.

${ }^{44}$ Cf. Fantham 1972, 103-4. 
da ovelha com um velho tolo, parece fazer parte de um repertório típico da fala de meretrizes plautinas. ${ }^{45}$ Elas, de fato, parecem versadas nesse tipo de "rebanho". Dessa maneira, acreditamos que n'O mercador a menção à ovelha, feita por Lisímaco durante a conversa com a meretriz Pasicompsa, evocaria o mote do tratamento que sua interlocutora, como outras meretrizes, daria aos velhinhos que delas se aproximassem. Contribui para essa impressão o uso do termo uetula (Mer. 525): adjetivo no grau diminutivo (que nesta passagem, sem dúvida, é depreciativo), ${ }^{46}$ usado por Pasicompsa para caracterizar a ovelha que ela havia de "receber". Como vimos, o mesmo termo, também no diminutivo, é registrado com função equivalente na citada passagem de Báquides (1129).

\section{CONSIDERAÇÕES FINAIS}

A análise das passagens plautinas em que, no confronto entre os sexos, ocorre associação entre os personagens masculinos e femininos e animais, trouxe algumas constatações e questões até o momento. Nessas passagens, observamos que tanto homens quanto mulheres são designados de modo recorrente como bestiae no discurso do sexo oposto. Em nossa amostra, no discurso feminino sobre os homens, tal recorrência se deu com relação a ovelhas, animal associado ao tipo cômico do velho, nas peças $O$ mercador (524-5) e Báquides (1121 $\left.1^{\mathrm{b}}, 1122\right)$.

Já no discurso masculino sobre mulheres, constatamos que, dentre as comédias plautinas apreciadas, cobra (anguis, 761) e cabra (capra, 229, 230) aparecem apenas na peça $O$ mercador, referindo-se aos seguintes tipos cômicos: o primeiro, a uma matrona; o segundo à matrona e também à meretriz. Mas algumas espécies de animais se repetem em referência a personagens femininos. Um desses animais é a cadela (canis), que nas peças Cásina (320) e Menecmos $(714,718)$ faz referência a um mesmo tipo cômico (a matrona).

\footnotetext{
${ }^{45}$ Além de aparecer nas mencionadas passagens de Báquides e $O$ mercador, o termo ouis é enunciado por uma meretriz na peça Asinária (v. 540). Segundo o Lexicon plautinum, o termo ouis é registrado com sentido próprio nas seguintes passagens: As. 540; Capt. 818; Mer. 524; Per.

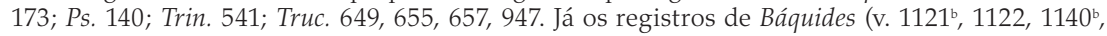
1141, 1142) são indicados como pasagens em que ouis é sinônimo de "tolo" (Cf. Lodge 1962). O ThLL aponta, nesse sentido, a ocorrência registrada no verso 173 de Persa. O Thesaurus indica ainda que a comparação entre características do animal e do homem, sobretudo a estupidez, é de "uso plautino" ("usu Plautino"), apontando as passagens de Báquides (1121 ${ }^{\text {a }}$ seq., 1140", 1141, 1142) e de O mercador (524). Acreditamos que ainda é preciso analisar as demais passagens no seu contexto, a fim de verificar se, apesar de não ser enunciado pela meretriz, o termo ouis não fica subentendido na sua fala, como no caso dos versos d'O mercador de que tratamos.

${ }^{46}$ Sobre esse e outros usos de diminutivos em Plauto, cf. Palmer 1977, 77.
} 
Alguns atributos podem ser apreensíveis do contexto: como vimos, n'O mercador, à capra equivalente à matrona se atribui a possibilidade de ela não aceitar a meretriz por quem o marido se apaixonara; em Menecmos, o termo canis está relacionado à mulher raivosa.

Para delimitarmos melhor a existência de um bestiário nas peças de Plauto, é ainda necessário verificar, em primeiro lugar, a abrangência de tais correspondências, isto é, se é possível observar uma relação mais constante entre determinada comparação com animal e determinado tipo de personagem da comédia palliata. Restam, assim, algumas questões. Por exemplo: a comparação com a cadela se dá sempre, ou prioritariamente, ao se tratar da matrona? E a comparação com a capra seria mais amplamente empregada para os tipos femininos em geral? É de se perguntar, também, se acaso seria possível notar, além disso, uma constância nas referências, i.e., se a determinado animal é atribuída sempre certa característica (ou, mais precisamente, certa qualidade ou defeito). Havendo ou não essa relação mais direta (quer entre animais e tipos de personagens, quer entre animais e atributos), nossa hipótese é de que será sempre preciso observar, a cada peça, até que ponto a comparação poderia ter ainda outros sentidos, ressaltados a depender do contexto em que é enunciada.

Ademais, é interessante procurar observar os ecos que tais comparações estabelecem entre uma peça e outra, como sugerimos na comparação com a cadela em Menecmos e Cásina - mas sempre levando em conta os pressupostos teóricos e limites de tais ecos ou possibilidades intratextuais no contexto das pesquisas plautinas. Em relação à leitura hodierna das comédias de Plauto, podemos pensar que, com acesso às vinte e uma peças e tempo para usufruí-las na ordem que prefira, o leitor moderno, na esteira de Sharrock (2009), pode associar comparações entre peças mais amplamente, como fizemos no caso d'O mercador e Báquides (na comparação entre velhos e ovelhas).

Por último, é importante ressaltar que nem sempre a equivalência entre animal e mulher é um recurso poético isolado, como pudemos notar ao nos voltarmos para os excertos apresentados. Na cena de Menecmos, estão envolvidas também referências mitológicas exageradas. N'O mercador, o caso é mais complexo: associa-se à comparação, que ainda pode envolver ironia dramática, um efeito de constrangimento, revelando-se o personagem do senex como um marido um tanto medroso.

Por meio de uma investigação mais ampla e aprofundada, pretendemos apreciar nas comédias em estudo os possíveis efeitos de sentido que esse arsenal de comparações gera especialmente para a caracterização do feminino em Plauto. De todo modo, na amostra analisada, já constatamos que o uso de referências animalescas no discurso sobre as mulheres (ou das 
mulheres) pode ser visto como um recurso poético, empregado, junto a outros meios linguísticos, para dramatizar jocosamente as relações de poder entre homem e mulher no palco plautino.

\section{REFERÊNCIAS}

Apollodorus. 1921. The Latin Library. Tradução para o inglês de James George Frazer. Vol II. Londres; Nova York: William Heinemann; G. P. Putnam's sons.

Barr, W. 1966. "Plautus, Menaechmi 838." Mnemosyne (Série 4) 19(1):50.

Bianco, M. M. 2003. Ridiculi senes: Plauto e i vecchi da commedia. Flaccovio Editore: Palermo.

Bonnet, H. 1958-1959. "Petit bestiaire de Virgile." Hum (RES) Gramm. 31:4-6.

Cardoso, I. T. 2001. "Matronae uirtuosae no Stichus de Plauto." Phaos 1:21-38.

Cardoso, I. T. 2005. Ars plautina. Tese de doutorado. Universidade de São Paulo.

Cardoso, I. T. 2006. Estico de Plauto. Campinas: Editora da Unicamp.

Chevallier, R. 1995. "Le bestiaire de Plaute." In Homme et animal dans l'antiquité romaine, Actes du Colloque de Nantes 1991, éditée par R. Chevallier, 327-50. Tours: Centre de Recherches A. Piganiol.

Corrêa, P. C. 2010. Um bestiário arcaico: fábulas e imagens de animais na poesia de Arquíloco. Campinas: Editora da Unicamp.

Costa, L. N. 2008. "O Anfitrião de Plauto: potencial e limites intertextuais." In XIV Seminário de Teses em Andamento, 2008, Campinas. Anais do Seta 3:571-84.

Costa, L. N. 2010. Mesclas genéricas na "tragicomédia" Anfitrião de Plauto. Dissertação de mestrado. Universidade de Campinas.

Duckworth, G. E. 1971. The Nature of Roman Comedy: A Study in Popular Entertainment. Princeton: Princeton University Press.

Dutsch, D. 2008. Feminine Discourse in Roman Comedy: on Echoes and Voices. Oxford: Oxford University Press.

Enk, P. J., ed. 1932a. Plauti Mercator cum prolegomenis, notis criticis, commentario exegetico: pars prior, prolegomena et textum continens. Leiden: A. W. Sijthoff.

Enk, P. J., ed. 1932b. Plauti Mercator cum prolegomenis, notis criticis, commentario exegetico: pars altera, commentarium continens. Leiden: A. W. Sijthoff.

Euripides. 1991. Hecuba. Introdução, tradução e comentários de Christopher Collard. Warminster: Aris \& Phillips Ltd..

Fantham, E. 1972. Comparative Studies in Republican Latin Imagery. Toronto e Buffalo: University of Toronto press.

Fantham, E. 1975. "Sex, Status, and Survival in Hellenist Athens: a Study of Women in New Comedy." Phoenix 29(1):44-74.

Fantham, E. 2011. Roman Readings: Roman Response to Greek Literature from Plautus to Statius and Quintilian. Berlim-Nova York: De Gruyter.

Fraenkel, E. 2007. Plautine Elements in Plautus. Traduzido por Tomas Drevivosky e Francis Muecke. Oxford: Oxford University Press. [Ed. or. 1922. Plautinisches im Plautus. Berlim: Weidmann]. 
Frangoulidis, S. A. 1994. "Palaestrio as Playwright in Plautus' Miles Gloriosus 209-12." In Studies in Latin Literature and Roman History 7, edited by C. Deroux, 72-86. Bruxelas: Latomus.

Franko, G. F. 2001. "Cleostrata in Charge: Tradition and Variation in Casina." In Greek and Roman Comedy: Translations and Interpretations of Four Representative Plays, edited by S. O'Brhyim, 169-88. Austin: University Press.

Gilula, D. 1980. "The Concept of bona meretrix: a Study of Terence's Courtesans." Rivista di filologia e di istruzione classica 108:142-65.

Glare, P. G. W., ed. 1968. Oxford Latin Dictionary. Oxford: Clarendon Press.

Grimal, P. 1963. Dictionnaire de la Mythologie Grecque et Romaine. 3. ed. Paris: Presses Universitaires de France.

Handley, E. W. 1970. "The Conventions of the Comic Stage and Their Exploitation by Menander." In Ménandre: sept exposés suivis de discussions, edited by E. G. Turner, 1-42. Genève: Fondation Hardt.

Homer. 2010. Iliad: book VI. Editado por Barbara Graziosi e Johannes Haubold. Cambridge: Cambridge University Press.

Houaiss, A.; Villar, M. S. 2009. Dicionário Houaiss da Língua Portuguesa. Rio de Janeiro: Editora Objetiva.

Hunter, R. L. 1989. The New Comedy of Greece \& Rome. Cambridge: Cambridge University Press.

Jocelyn, H. D. 2001. "Gods, Cult and Cultic Language in Plautus." In Studien zu Plautus' Epidicus, herausgegeben von Ulrike Auhagen, 261-96. Tübingen: Narr.

Keller, O. 1909, 1913. Die Antike Tierwelt, vols. 1-2. Leipzig: Verlag von Wilhelm Engelmann.

Leo, F. 1912. Plautinische Forschungen: zur Kritik und Geschichte der Komödie. Berlin: Weidmann.

Lodge, G. 1962. Lexicon Plautinum. Hildesheim-Nova York: Georg Olms Verlag.

Marx, F. 1899. Ein Stück unabhängiger Poesie des Plautus, viII Abhandlung, 1-34. Viena: Gerold.

Miotti, C. M. 2010. Ridentem dicere vervm: o humor retórico de Quintiliano e seu diálogo com Cícero, Catulo e Horácio. Tese de doutorado. Universidade de Campinas.

Moore, T. 1998. The Theater of Plautus: Playing to the Audience. Austin: Texas University Press.

Nauck, A. 1964. Tragicorum graecorum fragmenta. Hildesheim: Georg Olms Verlag.

Norman, D. 1928. Birds and Beasts of the Greek Anthology. Londres: Chapmann and Hall Ltd.

Norwood, G. 1963. Plautus and Terence. Nova York: Cooper square publishers inc..

Palmer, L. R. 1977. The Latin Language. Londres: Faber and Faber limited.

Paratore, E. 1983. História da Literatura Latina. Lisboa: Fundação Calouste Gulbenkian.

Plaute. 1933. Comédies: Bacchides - Captivi - Casina. Texto estabelecido e traduzido por Alfred Ernout. $9^{a}$ edição. Paris: Les Belles Lettres.

Plaute. 1936. Comédies: Menaechmi - Mercator - Miles Gloriosus. Texto estabelecido e traduzido por Alfred Ernout. 9. ed. Paris: Les Belles Lettres.

Plauti, T. M. 1975. Menaechmi. Editado, com introdução e notas de Nicholas Moseley e Mason Hammond. 9. ed. Cambridge, Londres: Harvard University Press. 
Plauto. 1998. Casina. Introdução, tradução e notas por Gioachino Chiarini. Roma: Carocci Editore.

Plautus. 1991. Bacchides. Edição com traduções e comentários de John Barsby. 3. ed. Wiltshire: Aris \& Phillips Ltd.

Plautus. 1976. Casina. Editado por W. T. MacCary e M. M. Willcock. Cambridge: Cambridge University Press.

Plautus. 1988. Casina - The Casket Comedy - Curculio - Epidicus - The Two Menaechmuses. Londres-Nova York: William Heinemann-G. P. Putnam's sons. (Reimp. 1 ed. 1917).

Plautus. 2002. The Merchant - The Braggart Warrior - The Haunted House - The Persian. Traduzido para o inglês por Paul Nixon. Cambridge; Londres: Harvard University Press. (Reimp. 1. ed. 1924).

Plautus. 1993. Menaechmi. Editado por A. S. Gratwick. Cambridge: Cambridge University Press.

Rocha, C. M. 2010. "Perfume de mulher": riso feminino e poesia em Cásina. Dissertação de mestrado. Universidade de Campinas.

Rocha, C. M. 2015. De linguado a lingua (ru)da: gênero e discurso das mulieres plautinae. Tese de doutorado. Universidade de Campinas.

Roscher, W. H., ed. 1884-1936. Ausführliches Lexikon der griechischen und römischen Mythologie, vol. 1. Leipzig: B. G. Teubner.

Schuhmann, E. 1977. "Der Typ der uxor dotata in den Komödien des Plautus." Philologus 121:45-65.

Sharrock, A. 2009. Reading Roman Comedy: Poetics and Playfulness in Plautus and Terence. Cambridge: Cambridge University Press.

Segal, E. 1987. Roman Laughter: the Comedy of Plautus. Nova York-Oxford: Oxford University Press.

Thesavrvs Lingvae Latinae, V.2. Leipzig: Teubner, 1931-1953.

Thesavros Lingvae Latinae, IX.2. Leipzig: Teubner, 1968-1981.

\section{*}

Title. Contributions to a feminine bestiary in Plautus

Abstract. The rivalry between men and women is a typical comic motif of the palliata - genre to which the 21 plays of the Roman playwright Titus Macius Plautus (III-II BC) are ascribed. Thus, the main point of these plays' intrigues is a kind of war, especially, between husbands and their wives. In this paper I intend to discuss the characterization of such a rivalry between sexes, observing examples of comparisons between animals and humans - involving not only female characters, but also male characters being compared to animals. In order to discuss this point, some passages of Bacchides, Casina, Menaechmi and Mercator will be considered.

Keywords. Plautus; comedy; women; animal imagery. 